\title{
A "era das diretrizes": a disputa pelo projeto de educação dos mais pobres
}

\author{
MARIA CIAVATTA \\ Universidade Federal Fluminense \\ Universidade do Estado do Rio de Janeiro \\ MARISE RAMOS \\ Universidade do Estado do Rio de Janeiro \\ Escola Politécnica de Saúde Joaquim Venâncio
}

\section{INTRODUÇÃO}

Diretrizes são orientações para o pensamento e a ação. As Diretrizes Curriculares Nacionais para o Ensino Médio (Brasil. CNE/CEB, 1998) e as Diretrizes Curriculares Nacionais para a Educação Profissional de Nível Técnico (Brasil. CNE/CEB, 1999), ${ }^{1}$ elaboradas no governo Fernando Henrique Cardoso (FHC), introduziram um discurso novo na educação brasileira: orientações explícitas de como deveria ser pensada e conduzida a ação educacional nas escolas. Seu comple-

1 As Diretrizes Curriculares Nacionais do Ensino Médio e da Educação Profissional Técnica de Nível Médio no Brasil foram estabelecidas pelos Pareceres da Câmara de Educação Básica do Conselho Nacional de Educação n. 15/1998 e 16/1999, o primeiro relativo ao ensino médio e o segundo à educação profissional, com as respectivas Resoluções n. 03/1998 e 04/1999. Doravante, quando a elas nos referirmos genericamente, utilizaremos a sigla DCN para designá-las. Quando forem específicas do ensino médio ou da educação profissional, utilizaremos as siglas DCNEM e DCNEP, respectivamente. 
mento normativo são os Parâmetros Curriculares Nacionais para o Ensino Médio (Brasil. MEC.SETEC, 2000a) e os Referenciais Curriculares Nacionais para a Educação Profissional de Nível Técnico (Brasil. MEC.SETEC, 2000b).

Significa, por acaso, que antes do governo FHC não teria havido orientações para o pensamento e a ação educacionais? $\mathrm{O}$ que significam os pareceres $^{2}$ que acompanharam as leis das reformas de $1^{\circ}$ e $2^{\circ}$ graus (lei n. 5692/71)? E a primeira Lei de Diretrizes e Bases da Educação Nacional (LDBEN), a lei n. 4.024/61, não deu orientações para a ação? Se já era uma "lei de diretrizes e bases", o que significou? De que outros instrumentos o governo dispunha para orientar o(s) sistema(s) educacional(ais)?

Dentro das pesquisas que vimos conduzindo sobre o tema, nosso objetivo é trazer à tona uma reflexão sobre o significado do tempo que estamos caracterizando como "a era das diretrizes" dado seu caráter discursivo inovador, divulgado pela mídia e pela abundante distribuição de materiais impressos, direcionados aos professores e às escolas. Paralelamente, apresentamos uma reflexão sobre a tendência global à regulação curricular que articula as reformas internas da educação com as reformas internacionais. Em terceiro lugar, mas não menos importante, está a questão de que a maioria da população brasileira - os trabalhadores, os desempregados, os subempregados, os mais pobres -, para ter um nível mínimo de educação, precisa do sistema público de ensino.

Havia um certo cinismo nos estudos de medição da pobreza que organizações internacionais desenvolviam na América Latina, nos anos 1970, na vigência das ditaduras nos países da região. A progressiva transformação desses países para sistemas democráticos representativos permitiu a reorganização das forças políticas, o fim da censura e a emergência dos estudos críticos. Hoje, uma breve incursão pelos estudos de serviço social que, de modo particular, convivem com os setores mais empobrecidos da sociedade, indica a quase ausência da palavra "pobres" e a incidência reiterada dos termos "questão social", "inclusão-exclusão", "desigualdade", evidenciando o foco mais na totalidade do sistema capital e nas contradições que ele gera.

2 Parecer n. 853/71; Parecer n. 889/71; Resolução n. 8/71; Parecer n. 45/7; Parecer n. 339/72; Resolução n. 2/72; Parecer n. 349/72; Parecer n. 355/72 (apud Romanelli, 1978, p. 267); Parecer n. 76/75. Os pressupostos da lei n. 5.692/71 seriam, de acordo com os autores que elaboraram um estudo para o INEP: "relações estreitas e racionais entre escola e mercado de trabalho; carência de técnicos de nível médio no país; valorização da escolaridade formal por parte das empresas; possibilidade de se atribuir ao sistema educacional maior responsabilidade pelo preparo de recursos humanos necessários à modernização do sistema econômico; viabilidade de uma proposta única de ensino médio para todo o País [...]" (Brasil. INEP, 1982, p. 28). 
No entanto, os pobres continuam a existir e a se multiplicar, como mostram as estatísticas nacionais ${ }^{3}$ e internacionais. Paulo Netto, em conferência no Chile, cita que "A concentração [de riqueza] chegou ao ponto de o patrimônio conjunto dos raros 447 bilionários que há no mundo ser equivalente à renda somada da metade mais pobre da população mundial - cerca de 2,8 bilhões de pessoas" (Mello, 1999, p. 260 apud Netto, 2007, p. 136, grifos do segundo autor) .

É em razão da ideologia conservadora que legitima os escassos recursos destinados à educação no Brasil que Mendes (1983) critica os tecnocratas brasileiros que, na época e ainda hoje, "julgam poder obter uma inteligentzia política, ou técnica ou burocrática, a baixo custo”:

Se se pode promover uma sociedade com cem ou mil pessoas exercendo o papel ditatorial, por que educar dez milhões ou cem milhões, para exercer a democracia? Se o "desengrossamento" do povo, até a limpidez é tão dispendioso e "incerto", por que não admitirmos a meia-educação? (p. 58)

É desta brutal realidade da educação na sociedade brasileira que tratamos, embora o tempo da pesquisa, neste trabalho, se inicie com o governo FHC, em 1994 - demarcado na educação pela lei n. 9.394/96, pelo decreto n. 2.208/97, as DCN e os PCN do final dos anos 1990 -, estendendo-se até 2011, que prolonga "a era das diretrizes" no final do governo Lula da Silva e início do governo Dilma Rousseff. Especificamente, são os documentos em processo no Conselho Nacional da Educação e os documentos alternativos de um Grupo de Trabalho intituído pelo Ministério da Educação, reunindo movimentos sociais, entidades científicas e setores do próprio Ministério.

Em termos de organização do texto, iniciamos pelas políticas neoliberais que caracterizaram o governo FHC, as diretrizes geradas no período e seus destinatários, os trabalhadores, os mais pobres que se educam nas escolas públicas; a seguir, tratamos de seus desdobramentos nas questões curriculares; em terceiro lugar, o ressurgimento do tema das diretrizes e a permanência da disputa de um projeto educacional para a grande população brasileira.

\section{DE LDBS, PARECERES E DIRETRIZES}

Cada época possui suas manifestações culturais próprias, emanadas da forma como se vive e se organiza a sociedade. Da mesma forma, produzem-se os

3 O Brasil tinha, em 2009, 31.705.528 matriculados no ensino fundamental. Dos 41\% das matrículas da rede pública, $36,3 \%$ eram ocupadas pelos $20 \%$ mais pobres. No mesmo período, 8.337.160 alunos estavam matriculados no ensino médio, sendo que dos $27,2 \%$ que se encontram na rede pública, $16,6 \%$ era ocupada pelos $20 \%$ mais pobres (CDES, 2011). 
discursos, suas justificativas e seus termos próprios para expressar o poder e suas determinações. Não sem contradições, mas sob o espírito inovador do capitalismo, geram-se novas sociabilidades adaptadas aos interesses dos grupos no poder. $\mathrm{O}$ autoritarismo assumido pelas ditaduras, como no Estado Novo (1937-1945) ou no Golpe Civil Militar (1964-1985), ou esmaecido nos governos centralizadores, com restrições à participação democrática nas decisões do Estado, tem tido seus próprios mecanismos de expressão das restrições impostas pelo Estado.

No caso da legislação educacional, a "Revolução de 1930" vem imbuída do espírito conservador do ideário da Primeira República, de seus coronéis e ideólogos (a exemplo de Oliveira Viana e de Alberto Torres). Um Estado nacional, centralizador, antiliberal e intervencionista (Shiroma; Moraes; Evangelista, 2003) impunha-se como indispensável à modernização do país. O trabalho e a educação como dois "temas de salvação nacional” conduziram à organização do trabalho 4 logo no início do governo Vargas, e da educação no início da década de 1940, em pleno Estado Novo.

A criação do Conselho Federal da Educação (1931), ${ }^{5}$ a organização do ensino superior (1931) e, principalmente, as Reformas Francisco Campos (1931-1932) normatizaram rigidamente a educação nacional, apoiando e apoiados pela Igreja Católica, apesar das tendências laicistas dos "pioneiros" ou "reformadores" da educação que, desde os anos 1920, atuavam nos estados organizando o ensino primário.

Nos anos 1940, com a presença forte dos empresários que necessitavam de trabalhadores adaptados ao espírito industrializante da época, as leis orgânicas do ensino secundário, técnico-profissional (industrial, comercial, agrícola), primário e normal introduziram padrões de organização e disciplina ${ }^{6}$ do espírito fabril para o fortalecimento da nacionalidade.

Em 1945, com o fim do governo Vargas e a democratização do país, ganha força a ideologia do desenvolvimento e o prestígio dos planos nacionais. ${ }^{7} \mathrm{~A}$ perspectiva de um futuro vitorioso e democrático transforma as reformas em lugar de

4 A criação do Ministério dos Negócios do Trabalho, da Indústria e do Comércio, a Justiça do Trabalho e as Juntas de Conciliação foi a resposta do Governo à intensa mobilização dos trabalhadores nas primeiras décadas do século, pela regulamentação das relações de trabalho (jornada de oito horas, repouso remunerado, limitação do trabalho de mulheres e crianças, proteção social (Franco; Simon, 1987).

5 Antes do atual Conselho Nacional de Educação, o país teve vários órgãos com funções similares desde o século XIX. No século XX, o Conselho Nacional de Educação foi instituído pelo decreto n. 19.850 de 11 de abril de 1931, na gestão Francisco Campos; o Conselho Federal de Educação foi criado pela LDBEN, lei n. 4.024 de 20 de dezembro de 1961. Foi substituído pelo Conselho Nacional de Educação pela lei n. 9.131/95, reiterado pela lei n. 9.394/96.

6 Os grifos em itálico indicam os termos enfatizados nos diversos instrumentos legais.

7 Sobre a ideologia do planejamento no Brasil, ver Ianni (1991). Uma análise das políticas de educação profissional no Brasil à luz dos Planos Nacionais de Desenvolvimento (PND), incluindo o da Nova República e o Programa Brasileiro de Qualidade e Produtividade, pode ser encontrada em Ramos (1995). 
luta social, a exemplo das Reformas de Base do governo João Goulart (1961-1964), de seu desdobramento em Plano Nacional de Alfabetização, inspirado em Paulo Freire, convivendo com a organização dos movimentos sociais. ${ }^{8} \mathrm{~A}$ disputa privatista pelos recursos e o pleito de fortalecimento da educação católica tomam forma na discussão público-privado e na organização do Movimento em Defesa da Educação Pública. A aprovação da Lei de Diretrizes e Bases da Educação Nacional consagra os termos diretrizes e bases e concilia os interesses públicos e privados da educação.

Com o golpe de 1964 instala-se um regime militar de rígidos controles nos sindicatos, nos meios de comunicação, nas universidades. Reformas e planos desdobram-se em planos decenais, programas de ação, programas estratégicos, reformas de ensino. Emanam do poder autoritário em consonância com as agências multilaterais, a exemplo do cumprimento da Carta de Punta Del Este (1961), o Plano Decenal da Educação da Aliança para o Progresso (1961 a 1970) e os Acordos MEC-USAID (1964 a 1968) (Shiroma; Moraes; Evangelista, 2003, p. 31-3). As reformas do ensino superior (lei n. 5.540/68) e do ensino de $1^{\circ}$ e $2^{\circ}$ graus (lei n. 5.692/71) incorporam a ideia de diretrizes e bases da educação nacional. A profissionalização compulsória do $2^{\circ}$ grau inaugura a época dos Pareceres que cumprem o papel de diretrizes normativas no sentido da organização e do funcionamento do ensino. ${ }^{9}$

Ao mesmo tempo, amordaçam-se os movimentos sociais e o Movimento de Educação de Base transforma-se no Movimento Brasileiro de Alfabetização ${ }^{10} \mathrm{com}$ a substituição da política subversiva pela assepsia de métodos e técnicas.

Solapa-se a concepção de bases para a educação pública que acabou, mais uma vez, subsumida à ideia de diretrizes. No caso da lei n. 4.024/61, pela partilha dos recursos públicos com o setor privado; no caso da lei n. 5.692/71, primeiro, porque o regime militar reduziu a aplicação de recursos na educação para menos de 3\% do orçamento da União, e segundo, porque o salário-educação, que fora criado para subsidiar o ensino primário de quatro anos, tornado ensino de $1^{\circ}$ grau de oito anos, foi gradativamente repassado ao setor privado em cumprimento a interesses clientelistas de políticos e empreiteiros (Shiroma; Moraes; Evangelista, 2003, p. 39).

8 São expressões da organização da sociedade civil em contraste com a centralização do Estado, o Movimento em Defesa da Escola Pública em oposição às pressões conservadoras e privatistas, as Ligas Camponesas, a organização dos sindicatos rurais e urbanos, os Centros de Cultura Popular da União Nacional dos Estudantes, o Movimento de Educação de Base, os Movimentos de Cultura Popular.

9 "Pareceres são proposições em que as Câmaras e comissões se pronunciam em matérias a elas submetidas. [...] As Resoluções aprovadas pelo Plenário do Conselho são atos de caráter normativo firmados pelo Presidente [...]" (Rothen, 2004, p. 2).

10 O Movimento Brasileiro de Alfabetização (MOBRAL), criado pela lei n. 5.379, de 15 de dezembro de 1967, propunha a alfabetização funcional de jovens e adultos. No contexto do acirramento da ditadura civil-militar, assume o lugar da alfabetização realizada pelos movimentos sociais a exemplo do Movimento de Educação de Base (MEB), "De pé no chão também se aprende a ler" e outros. 
Com o fim do "Milagre econômico" em meados dos anos 1970 e fortes pressões sobre o regime militar, planos e programas foram implementados junto às populações das áreas mais pobres. ${ }^{11}$ Ainda no final dessa década, a profissionalização universal e compulsória empreendida pela lei n. 5.692/71 é flexibilizada pelo Parecer do CFE n. 75/76 e consolidada pela lei n. 7.044/82 com as seguintes alterações: a) substituição de "qualificação para o trabalho" por "preparação para o trabalho" (caput do art. $1^{\circ}$ ); b) absorção de "preparação para o trabalho" como elemento da "formação integral do aluno" em caráter obrigatório no ensino de $1^{\circ} \mathrm{e}$ $2^{\circ}$ graus (art. $4^{\circ}$, parágrafo $1^{\circ}$ ); e c) conversão da habilitação profissional em opção dos estabelecimentos de ensino (art. $4^{\circ}$, parágrafo $2^{\circ}$ ).

Ao final da década de 1980, o processo de redemocratização das relações institucionais, somado às mudanças no mundo do trabalho e à elaboração de uma nova $\mathrm{LDB}$, começaram a pautar na sociedade o debate sobre uma formação de novo tipo que incorporasse dimensões políticas comprometidas com a cidadania. Existiu uma mobilização em torno da reformulação curricular no interior das instituições federais pela implantação de um currículo comum da educação tecnológica baseada na conexão entre ensino e trabalho, excluindo a oposição entre cultura e profissão.

A aprovação da LDB em 1996 significou, na verdade, somente o início de um movimento de reformas na educação brasileira, que tomou corpo mediante as regulamentações posteriores realizadas na estrutura educacional - no caso da educação profissional, o decreto n. 2.208/97 - e outras no campo conceitual, objetivadas, no âmbito da educação básica, pelas Diretrizes Curriculares Nacionais, sejam do ensino fundamental, do ensino médio ou da educação profissional de nível técnico. A elaboração dessas diretrizes ficou a cargo da União - com a colaboração do Conselho Nacional de Educação - considerando sua função de estabelecer, em colaboração com os estados, o Distrito Federal e os municípios, competências e diretrizes para a educação infantil, o ensino fundamental e o ensino médio, que nortearão os currículos e seus conteúdos mínimos, de modo a assegurar formação básica comum. (Brasil, 1996, art. $9^{\circ}$, inciso IV)

Lopes (2008) ajuda-nos a reconhecer a relação entre a reforma curricular empreendida no Brasil e o movimento internacional correspondente. Ela refere-se à crescente subordinação dos Estados nacionais às exigências das agências multilaterais, como a Organização das Nações Unidas para a Educação, a Ciência e a Cultura (UNESCO) e os Bancos Mundial e Interamericano de Desenvolvimento (BIRD e BID). Acrescentamos a essas, ainda, a Comissão de Estudos Econômicos para a América

11 "Um sem-número de projetos foi desencadeado nessa direção: Polo Nordeste, EDURURAL, Programas de Ações Socioeducativas e Culturais para as Populações Carentes do Meio Urbano (PRODASEC) e do Meio Rural (PRONASEC), Programa de Educação Pré-Escolar, entre vários outros, com a inevitável pulverização e a fragmentação da outrora coesa política educacional" (Shiroma; Moraes; Evangelista, 2003, p. 41-42). 
Latina (CEPAL) e, particularmente em relação à educação profissional, a Organização Internacional do Trabalho (OIT), em especial por meio do Centro Interamericano para o Desenvolvimento da Formação Profissional (CINTERFOR). Segundo a autora,

[...] parte-se do reconhecimento de que, com o advento das políticas econômicas genericamente denominadas neoliberais, há acentuada submissão das políticas educacionais aos mecanismos de definição e de avaliação dos conteúdos curriculares pelo Estado, bem como aos mecanismos de regulação do mercado. (Lopes, 2008, p. 21)

Exemplos de países que tiveram o currículo como cerne de suas reformas foram Espanha, Inglaterra e País de Gales, introduzindo os temas transversais nos referenciais curriculares nacionais, essas igualmente presentes nos Parâmetros Curriculares Nacionais para o ensino fundamental no Brasil. Em nosso país, também a interdisciplinaridade e o currículo por competências são propostos para o ensino médio e as diretrizes da educação profissional se basearam em competências. Segundo Lopes (2008), em Portugal propôs-se o currículo por áreas (orientação também presente nos documentos oficiais no Brasil, juntamente com as competências); no Chile, os objetivos transversais; e, no México, novamente as competências, com ênfase nas de caráter transversal.

O relatório Jaques Delors (1998), originado da Reunião Internacional sobre Educação para o Século XXI da UNESCO, influenciou esse movimento com a formulação das quatro grandes necessidades de aprendizagem ou os quatro pilares da educação: aprender a conhecer, aprender a fazer, aprender a conviver e aprender a ser. No Brasil, as DCNEM e as DCNEP, ambas baseadas em competências, tiveram como fundamento os princípios axiológicos expostos nas respectivas diretrizes, na verdade, uma releitura desses pilares. Nesse documento e em outros que orientaram as reformas, a principal finalidade da educação contemporânea seria a formação de personalidades flexíveis para a adaptação à realidade instável e incerta. A era das diretrizes coincide, assim, com a era das incertezas. ${ }^{12}$

\section{O CURRÍCULO E A ÁREA TRABALHO E EDUCAÇÃO}

A direção que assume a relação trabalho e educação nos processos formativos não é inocente. Traz a marca dos embates que se efetivam no âmbito do conjunto das relações sociais, sendo parte da luta hegemônica entre capital e trabalho. Assim, ao configurar uma área de conhecimento, os estudos em Trabalho e Educação têm

12 O termo "incertezas", embora não tenha um estatuto teórico estabelecido, é de uso corrente nos estudos de sociologia do trabalho e outros, para caracterizar a instabilidade das ideias e da perspectiva de futuro nos tempos atuais. Entre outros, ver Harvey (1992) e Ciavatta (1998). 
a categoria trabalho e sua historicidade no modo de produção capitalista como central, compreendendo a relação com a educação como uma unidade constituinte historicamente da formação humana, contraditoriamente cindida com a formalização da educação escolar e com a instituição de um tipo de ensino próprio para a classe trabalhadora, distinto daquele destinado às elites. Nesse sentido, os estudos nessa área buscam captar a dinâmica histórica das relações e processos de trabalho na sociedade capitalista em geral e, especificamente, no Brasil, e as mediações contraditórias entre essa dinâmica, as políticas e os processos de educação da classe trabalhadora. ${ }^{13}$

Assim, tendo como base teórica a crítica à economia política, a educação da classe trabalhadora no Brasil tem sido estudada especialmente sob o enfoque econômico-político. O conhecimento escolar era um tema mais afeto aos campos da didática e do currículo. Como demonstra Saviani (2007), a difusão das teorias crítico-reprodutivistas da educação na década de 1970 deixou poucas margens para que se propusesse uma nova maneira de lidar com a escola. A teoria crítica do currículo, por sua vez, representada em parte pela Nova Sociologia do Currículo, voltou-se para o exame das relações entre currículo e estrutura social, currículo e cultura, currículo e poder, currículo e ideologia, currículo e controle social (Moreira; Silva, 2001).

Em contraposição às teorias crítico-reprodutivistas, a compreensão da escola como instância de organização da cultura e, assim, como aparelho privado de hegemonia (Gramsci, 1991) colocou novas questões para a área. O programa marxiano de educação e os estudos de Antonio Gramsci, a partir de seus leitores, contribuíram para a difusão da concepção de educação tecnológica e politécnica e da formação omnilateral como a utopia educacional revolucionária da classe trabalhadora, tendo o trabalho como princípio educativo. Esta expressão, a propósito, sintetizou a questão científica e ético-política central da área, motivando estudos sobre o seu significado e a sua possibilidade teórica e prática na sociedade capitalista. O Projeto de LDB original da Câmara Federal dos Deputados tentou contemplar esse princípio na organização da educação básica, mas o seu esvaziamento contribuiu para a reforma conservadora realizada no governo FHC.

Se a reforma de toda a educação básica e superior teve implicações para a educação dos trabalhadores, aquela que incidiu sobre o ensino médio foi a mais significativa. Após a importante luta social por um projeto de educação unitária, tecnológica e politécnica, visando à formação omnilateral dos trabalhadores e tendo o trabalho como princípio educativo, a educação técnico-profissional de nível médio foi separada mecanicamente do ensino médio e tornada paralela ou subsequente a ele. Propósitos, sentidos e conteúdos de cada uma dessas formações

13 Referimo-nos a Trein e Picanço (1995), Trein (1996), Ciavatta e Trein (2003), Bomfim (2006). 
foram construídos, difundidos e implementados como política curricular por meio das DCNEM e DCNEP em relação à qual a área Trabalho e Educação precisou se manifestar. De alguma maneira, no plano da superestrutura - ao menos na esfera da educaçãoexplicitava-se, claramente, a direção política e cultural que a classe dominante visava dar à sociedade, considerando a crise ampliada do capital e sua manifestação específica na organização da produção, designada genericamente de reestruturação produtiva.

Assim, a incorporação do tema currículo pela área Trabalho e Educação coincide com o movimento de regulamentação de todos os níveis e modalidades educacionais na forma das DCN. Este, por sua vez, caracterizou o processo de reformas na educação brasileira convergente com o mesmo movimento internacional, evidenciando a política curricular como estratégia ideológica de formação dos sujeitos para a sociabilidade contemporânea. As DCN constituíram peças textuais que apresentam a concepção orientadora do currículo nos respectivos níveis e modalidades de ensino, reunidas em um parecer denso e circunstanciado jurídica, histórica e filosoficamente, o qual se objetiva na forma de uma resolução, com efeito de lei, que visa dar operacionalidade às orientações conceptuais dispostas no parecer.

O Conselho Nacional de Educação se constituiu numa instância de poder integrada ou paralela, eis uma questão - ao Ministério da Educação. No projeto original de LDB este foi concebido como autônomo em relação ao executivo. Essa condição convergia com a proposição de um Sistema Nacional de Educação orgânico e coerente - e com a instituição do Fórum Nacional de Educação. Este último seria o espaço de discussão e formulação da política educacional, enquanto o Conselho, o espaço regulamentador. A característica de ambos seria a representação substantiva da sociedade civil, dando efetividade organizativa ao Estado ampliado.

Sabemos que nem o Sistema nem o Fórum Nacional de Educação foram logrados na lei n. 9.394/96. O Conselho Nacional de Educação, por sua vez, adquiriu estatuto de órgão de assessoramento ao Ministério da Educação. Parte de sua composição advém da sociedade civil, porém, como sugestão, já que a indicação final de cada conselheiro cabe ao Ministro da Educação. Como instância de poder, torna-se campo de disputa por hegemonia entre classes e frações de classes, sendo a política curricular o objeto específico dessa disputa.

\section{AS DIRETRIZES CURRICULARES NACIONAIS DOS ANOS 2010 E A DISPUTA PELO PROJETO DE EDUCAÇÃO DOS MAIS POBRES}

Um discurso comum entre os apreciadores do tema educação é a suposta inutilidade das teses e dissertações que "ficariam relegadas à crítica roedora dos ratos", parafraseando a ironia de Marx e Engels sobre um de seus mais importantes livros - $A$ ideologia alemã -, tardiamente divulgado e reconhecido, entre outras coisas, por sua revolucionária concepção da "história como a produção social da existência" (Bruni; Nogueira, 1979, p. 9). 
Ironicamente, teses e dissertações, no campo das ciências humanas e sociais, contrariando o espírito cinza nebuloso de vinte anos de ditadura civil-militar, mantêm-se ampliando os horizontes da compreensão da realidade do país. Além dessas, as forças políticas e sociais libertadas das amarras do pensamento autoritário continuam organizando-se em defesa de amplos setores emudecidos pela tarefa ingente de comer cada dia e pela ignorância do mundo letrado que orienta decisões nacionais pouco democráticas. Shiroma, Moraes e Evangelista (2003), tratando das políticas educacionais, destacam como nos anos do govermo FHC as decisões fecharam-se, distante "dos fóruns democráticos e do debate", "do rico consenso que educadores brasileiros construíram sobre pontos básicos da educação brasileira, na luta pela democratização do país” (p. 11).

Mais uma vez, no final do governo Lula da Silva e nos primeiros meses do governo Dilma Rousseff, somos surpreendidos com a ressuscitação das Diretrizes Curriculares Nacionais. Emanadas do CNE em 1998 para orientar a implantação do decreto n. 2.208/97, foram maquiadas e reiteradas em 2004, após a revogação do mesmo decreto e a exaração do decreto n. 5.154/04. Novamente em 2010, o relator da Câmara de Educação Básica, Professor Cordão, ignorou a particularidade da introdução da alternativa formação integrada ao lado das formas concomitante e subsequente de articulação entre ensino médio e educação profissional.

O documento veio a lume no primeiro semestre de 2010, e o primeiro documento alternativo de um Grupo de Trabalho, promovido pelo Ministério da Educação, reunindo movimentos sociais, entidades científicas e setores do próprio Ministério, começou a ser elaborado em meados do mesmo ano (Brasil, 2010). Em reunião convocada pelo Ministério da Educação e Secretaria de Educação Profissional e Tecnológica (MEC/SETEC), realizada em 23 de maio de 2011, os participantes elaboraram um documento que subsidiou a carta encaminhada ao Presidente da Câmara de Educação Básica do CNG, divulgada neste número da Revista Brasileira da Educação na seção Documentos, expondo suas divergências com o Parecer Cordão (Brasil. CNE/CEB, 2011) e apresentando os pressupostos básicos do documento alternativo que, neste texto, servirá de base para a análise crítica de alguns aspectos mais gerais, fundantes do mesmo Parecer. ${ }^{14}$

A proposta do Parecer Cordão, relativo à atualização das DCNEP, inicia-se com um histórico da educação profissional técnica de nível médio a partir da LDB de 1996, destacando o conjunto de regulamentações provocadas pelo decreto n. 2.208/97. Curiosamente, ressalta que essas permaneceram plenamente compatíveis com o decreto n. 5.154/2004, o que teria exigido do Conselho somente sua atualização promovida pelo Parecer CNE/CEB n. 39/2004. Nesse momento, a finalidade de um novo parecer seria

14 Em janeiro de 2011, o Relator, Professor Aparecido José Cordão, apresentou ao CNE/CEB a nova versão de seu Parecer (Brasil. CNE/CEB, 2011), incorporando expressões próximas aos conteúdos do documento alternativo do Grupo de Trabalho, mas mantendo as ideias centrais de sua proposta. 
principalmente explicitar orientações complementares em relação a eventuais pontos de divergência, considerando, inclusive, as alterações introduzidas pela lei n. 11.741/2008.

Assim, não se deve estranhar que o conteúdo da proposta reitere os princípios que orientaram a reforma da educação profissional e do ensino médio dos anos 1990. Afirma-se, textualmente, que os respectivos princípios balizadores e as orientações de procedimentos já se encontram claramente delineados nos documentos produzidos pelo Conselho sobre a matéria.

Em seguida, anuncia que a proposta será detalhada em seis partes, a saber: escolha do curso e de parcerias; otimização do ingresso nos cursos, pela avaliação diagnóstica de competências profissionais constituídas; recursos físicos, didáticos e institucionais suficientes para a oferta dos cursos; parâmetros de carga horária presencial para cursos desenvolvidos na modalidade de educação a distância, especialmente em saúde; proposta pedagógica contextualizada e avaliação do egresso como essenciais na sua constante atualização; profissionais envolvidos no processo educativo da educação profissional e tecnológica.

O texto ainda explicita e analisa as alterações promovidas na LDB pela lei n. 11.741/2008, relativas à educação profissional e tecnológica, incluindo a educação de jovens e adultos. Reiteramos que tais alterações não exigiriam muito mais do que esclarecimentos e aprofundamentos de alguns princípios e orientações. $\mathrm{O}$ relator reconhece que a educação profissional se situa na confluência de dois direitos fundamentais do cidadão: o direito à educação e o direito ao trabalho.

Se não há discordâncias a esse respeito, nem quanto à necessidade de superação das qualificações profissionais restritas aos postos de trabalho, também afirmada pelo parecer, o mesmo não se pode afirmar sobre a suposição de que isto "determina a emergência de um novo modelo de educação profissional centrado no desenvolvimento de competências profissionais por eixo tecnológico" (Brasil. CNE/CEB, 2011, p. 17).

Mas para defender esse ponto de vista, o parecer, após ratificar os princípios axiológicos definidos pela DCNEM de 1998 com base nos quatro pilares da educação da UNESCO, aqui comentados, dedica dez páginas para expor os fundamentos de sua proposta curricular baseada na "CHAVE" para o entendimento do compromisso da educação profissional e tecnológica com o desenvolvimento de competências profissionais" (Brasil. CNE/CEB, 2011, p. 20) Uma vez que este é o núcleo central da concepção de formação humana e educação profissional condensada nesse documento, é sobre ele que versa a análise apresentada a seguir.

\section{A "CHAVE" do trabalhador competente e adaptado}

O núcleo das diretrizes curriculares propostas no Parecer Cordão é o currículo baseado em competências, a partir do qual analisamos as concepções de currículo em disputa na educação profissional, o problema da relação teoria e prática, a flexibilidade curricular transformada em fragmentação, e a interdisciplinaridade. 
A “CHAVE", sigla que reúne os componentes da competência (conhecimentos, habilidades, atitudes, valores e emoções), é o eixo de todo o argumento do parecer.

A visão da educação como chave para algum lugar não é nova. Incluem-se chave para o futuro, para o desenvolvimento, para o crescimento, para um mundo melhor, para o sucesso profissional. Expressões como essas fazem parte do senso comum. Trata-se, portanto, de uma metáfora reificadora do poder econômico e social da educação tão difundido pela Teoria do Capital Humano nas décadas de 1950 a 1970, e, por isto mesmo, bastante sedutora.

Contemporaneamente, o termo "chave" também forma um substantivo composto com competência: as competências-chave, sinônimo de competências básicas ou fundamentais. Um marco internacional dessa formulação é o Programa Internacional de Avaliação de Estudantes (PISA), projeto de avaliação comparativa da Organização para Cooperação e Desenvolvimento Econômico (OCDE), destinado à avaliação de estudantes de 15 anos de idade, fase, em média, de conclusão da escolaridade básica. No âmbito desse programa, a OCDE desenvolveu o Projeto "Definindo e Selecionando Competências-chave" (DeSeCo), concluindo por três grupos de competências-chave, a saber: "interagir no seio de grupos socialmente heterogêneos; agir de modo autônomo; utilizar recursos ou instrumentos de modo interativo"15 (Sacristán, 2011, p. 42).

Permeado de sentido metafórico na educação e tendo um uso supostamente científico na teoria das competências, o termo chave transforma-se em "CHAVE" na proposta de DCNEP de 2010. O relator lembra que o Parecer CEB/CNE n. 16/99 já definia a competência como "capacidade de mobilizar, articular e colocar em ação, valores, habilidades e conhecimentos necessários para o desempenho eficiente e eficaz de atividades requeridas pela natureza do trabalho" e que, posteriormente, o Parecer CNE/CP n. 29/2002 acrescentou os fatores "atitudes e emoções”. Para ele,

[...] assim, clarificou-se a "CHAVE" que abre a porta para o entendimento do conceito de competência profissional, como sendo o desenvolvimento da capacidade de mobilizar, articular e colocar em ação, "Conhecimentos, Habilidades, Atitudes, Valores e Emoções" (sigla "CHAVE”), para responder, de forma criativa, aos novos desafios da vida cidadã do trabalhador. (Brasil. CNE/CEB, 2011, p. 20)

Os componentes da competência podem ser descritos também como o saber, o saber fazer, o saber ser e o saber conviver. A competência existiria quando esses saberes são mobilizados e articulados para a resolução de problemas no campo de atuação profissional. A competência visaria ao desempenho eficiente e eficaz e este, segundo o parecer, é o que verdadeiramente pode ser utilizado para aferir e avaliar essas competências profissionais. Por isso, a avaliação em situações de ensino e

15 O sumário executivo desse projeto pode ser consultado em: <http://www.oecd.org/ dataoecd/47/61/35070367.pdf>. 
aprendizagem deveria ser procedida com base em indicadores de desempenho e parâmetros claramente definidos pelos docentes.

Os contextos de exercício da competência são situações concretas de trabalho. A "CHAVE" abriria o universo da laboralidade ao trabalhador, por proporcionar um "saber operativo, dinâmico e flexível” (Brasil. CNE/CEB, 2011, p. 22). Supõe-se que, assim, o trabalhador poderia se manter constantemente em atividade produtiva e geradora de renda em contextos socioeconômicos cambiantes e instáveis, podendo transitar por diversas atividades. Em síntese, a competência para a laboralidade seria a base da polivalência.

A formação voltada para esse tipo de competência estaria mais preocupada com o desenvolvimento da capacidade de mobilizar e articular conhecimentos, habilidades, valores, atitudes e emoções do que com o conjunto de conhecimentos e habilidades (Brasil. CNE/CEB, 2011 ). Há uma relação nessa abordagem com o conceito de competência formulado pela OCDE, pelo qual

[...] uma competência é mais que conhecimentos e habilidades, é a capacidade de enfrentar demandas complexas em um contexto particular, um saber fazer complexo, resultado da integração, mobilização e adequação de capacidades, conhecimentos, atitudes e valores utilizados de modo eficaz em situações reais. (Gómez, 2011, p. 84)

No modelo taylorista-fordista de produção, no qual predomina o trabalho prescrito, as análises ocupacionais trataram de descrever competências como sinônimo de desempenhos eficientes e eficazes a serem reproduzidos na formação como os objetivos operacionais. Neste caso,

[...] as competências são consideradas comportamentos observáveis e sem relação com atributos mentais subjacentes, enfatizam a conduta observável em detrimento da compreensão, podem ser isoladas e treinadas de maneira independente, e são agrupadas e somadas sob o entendimento de que o todo é igual a mera soma das partes. (idem, p. 83)

Os modelos flexíveis de produção valorizam também o comportamento, porém, de natureza transversal, tais como trabalhar em equipe, ter iniciativa, saber comunicar-se, dentre outras. São comportamentos de ação e interação que caracterizam a competência numa perspectiva construtivista e holística ${ }^{16}(\mathrm{idem})$.

16 Segundo esse autor, a competência nessa perspectiva corresponde a um complexo sistema de reflexão e ação que inclui conhecimentos, habilidades, atitudes, valores e emoções, isto é, a "CHAVE", conforme o relator do parecer aqui analisado. 
No Brasil, ao orientar as DCN da educação básica, conferiu-se forte ênfase à dimensão comportamental em detrimento da formação teórica. Essa mesma concepção orientou a formulação das DCNEP, porém as competências foram descritas como desempenhos operacionais, sugerindo, indiretamente, a transposição de situações de trabalho para o currículo e a realização do ensino de tipo condutivista. Como vimos no parecer em análise, o desempenho é reiterado como a unidade manifestável e avaliável da competência. De fato, se as competências compõem a subjetividade do trabalhador (nos plano cognitivo e sociointerativo), qualquer enunciado objetivo só pode reduzi-las a desempenhos.

Aqui se encontra um problema sério na teorização sobre a competência. A ação competente no trabalho é guiada por um tipo de saber próprio que é síntese entre o conhecimento teórico aprendido na formação e a experiência. $\mathrm{Ou}$, em outras palavras, síntese entre teoria e prática. $\mathrm{O}$ currículo não pode antecipar a experiência profissional; pode, no máximo, representá-la (em situações práticas de aprendizagem, sejam aulas ou estágios).

O parecer, porém, enfatiza a prática como a própria metodologia de ensino, sendo a prática profissional organizadora do currículo. Conhecimentos adquiridos na prática deveriam se converter em novos conteúdos de ensino e as metodologias deveriam propiciar o "desenvolvimento de capacidades para resolver problemas, comunicar ideias, tomar decisões, ser criativo e cooperativo, ter iniciativa, autonomia, flexibilidade, espírito de equipe, responsabilidade, interesse e atenção nos trabalhos desenvolvidos" (Brasil. CNE/CEB, 2011, p. 20).

Retoma-se a ideia de se deslocar o foco das atividades de ensino para os resultados de aprendizagem. Essa ideia só é possível numa lógica espontaneísta de ensino, já que, na efetiva relação pedagógica, processo e resultado de ensino-aprendizagem não se separam. Mas sua assimilação tão frequente no senso comum encontra respaldo numa visão pragmática da educação.

Evidenciam-se, assim, nessa proposta, o foco nos comportamentos e a ênfase na metodologia. $\mathrm{O}$ destaque aos conhecimentos adquiridos na prática como novos conteúdos de ensino é complementado pela defesa da valorização da experiência dos alunos. As experiências, de fato, constituem um primeiro passo do método histórico: partir do concreto empírico, analisá-lo buscando as mediações contraditórias e ordená-las no plano do pensamento como forma de apreendê-la concreta e criticamente para além da experiência sensível. Mas, se oposta ao conhecimento científico, este tomado somente como recurso para o desenvolvimento de competências, a valorização da experiência do aluno leva à reificação do saber prático em detrimento da compreensão dos fenômenos e dos próprios fundamentos, pertinência e limites desse saber. 


\section{As concepções de currículo na educação profissional}

A questão curricular na relação trabalho e educação é uma questão das DCN que tem um sentido crítico no documento alternativo ao texto do CNE/CEB. Sua análise torna-se um problema da relação entre parte - a formação que a escola pode proporcionar - e a totalidade das relações sociais de produção, e entre teoria - os conhecimentos científicos e técnicos aprendidos na formação - e a prática real que desafia e reconstrói esses conhecimentos. Isto é radicalmente distinto de se pensar o currículo como o enunciado de competências e seus respectivos componentes e a definição de situações e metodologias de aprendizagem. Mas é esse tipo de currículo que o parecer entende ser capaz de dar ao trabalhador, a "CHAVE" de sua existência, que se reduz aos mecanismos de adaptação ao mercado de trabalho.

O documento elaborado em contraposição a esse parecer vê na formação integrada a chave para o trabalhador apreender as contradições das relações sociais de produção e produzir sua existência com o seu trabalho. Não por adaptação à realidade dada, mas em confronto com ela e visando à sua transformação, o que supõe a compreensão das relações sociais subjacentes a todos os fenômenos (Frigotto; Ciavatta; Ramos, 2005, p. 85).

A ideia de formação integrada sugere superar o ser humano dividido historicamente pela divisão social do trabalho entre a ação de executar e a ação de pensar, dirigir ou planejar. Trata-se de superar a redução da preparação para o trabalho ao seu aspecto operacional, simplificado, escoimado dos conhecimentos que estão na sua gênese científico-tecnológica e na sua apropriação histórico-social. Como formação humana, o que se busca é garantir ao adolescente, ao jovem e ao adulto trabalhador o direito a uma formação completa para a leitura do mundo e para a atuação como cidadão pertencente a um país, integrado dignamente à sua sociedade política. (Brasil, 2010, p. 40)

O trabalho é princípio educativo nessa formação, o que equivale a afirmar que o ser humano é produtor de sua realidade e, por isso, se apropria dela e pode transformá-la. Equivale a afirmar, ainda, que nós somos sujeitos de nossa história e de nossa realidade. Em síntese, o trabalho é a primeira mediação entre o homem e a realidade material e social. O trabalho também se constitui como prática econômica que na sociedade moderna vem se tornando fundamento da profissionalização. Mas integrada à ciência e à cultura a formação para o trabalho se opõe à redução da formação para o mercado de trabalho. Antes, ela incorpora valores ético-políticos e conteúdos históricos e científicos que caracterizam a práxis humana.

Por essa ótica, a educação profissional não é meramente ensinar a fazer e preparar para o mercado de trabalho, mas é proporcionar a compreensão das 
dinâmicas socio-produtivas das sociedades modernas, com as suas conquistas e os seus revezes, e também habilitar as pessoas para o exercício autônomo e crítico de profissões, sem nunca se esgotar a elas (Brasil. MEC, 2010). Essa concepção de educação profissional implicaria outras diretrizes curriculares e é isto a que o documento elaborado em contraposição ao parecer se propõe.

Quando afirmamos que a questão curricular, vista na perspectiva da relação trabalho e educação, se torna um problema da relação entre a particularidade dos processos produtivos e a totalidade das relações sociais de produção, partimos do pressuposto de que o real é um todo estruturado, dialético, no qual ou do qual um fato qualquer (classe de fatos, conjunto de fatos) pode vir a ser racionalmente compreendido (Kosik, 1976). A posição da totalidade coloca-se em antítese ao empirismo e ao pragmatismo que parecem orientar a atual proposta de DCNEP. Esses consideram as manifestações fenomênicas e causais como a própria realidade, não chegando a atingir a compreensão dos processos históricos da realidade. A posição da totalidade, ao contrário, compreende a realidade nas suas íntimas leis e revela, sob a superfície e a casualidade dos fenômenos, as conexões internas.

Segundo Kosik (1976), cada fato ou conjunto de fatos, na sua essência, reflete toda a realidade com maior ou menor riqueza ou completude. Assim, a possibilidade de se conhecer a totalidade a partir das partes é dada pela possibilidade de se identificar os fatos ou conjunto de fatos que deponham mais sobre a essência do real; e, ainda, de distinguir o essencial do acessório, assim como o sentido objetivo dos fatos. Para fins formativos, isso significa identificar componentes e conteúdos curriculares que permitam fazer relações sincrônicas e diacrônicas cada vez mais amplas e profundas entre os fenômenos que se quer apreender - neste caso, uma profissão - e a realidade em que eles se inserem. ${ }^{17}$

Os conhecimentos específicos de uma profissão - mesmo ampliados para uma área profissional ou um eixo tecnológico - não são suficientes para proporcionar a compreensão das relações sociais de produção. Por isto a defesa da integração desses conhecimentos com os de formação geral. Mesmo que os processos produtivos em que se pode exercer uma profissão sejam particularidades da realidade mais ampla, é possível estudá-los em múltiplas dimensões - econômica, social, política, cultural e técnica, dentre outras - de forma que, além dos conhecimentos específicos, os de formação geral tornam-se também uma necessidade.

Não se trata somente de contextualizar a formação, entendida pelo Parecer Cordão (Brasil. CNE/CEB, 2011) como a integração da teoria à vivência da prática

17 A análise aqui apresentada está presente, originalmente, em Ramos (1995), apropriada no Documento Base da Educação Profissional Técnica de Nível Médio (Brasil. MEC. SETEC, 2007) e, recentemente, adaptada para o documento elaborado em contraposição a atual proposta de DCNEP (Brasil, 2010). 
profissional dos alunos. Trata-se de relacionar parte e totalidade, conhecimentos gerais e específicos, contemporaneidade e historicidade. A interdisciplinaridade torna-se, então, uma necessidade - princípio organizador do currículo e método de ensino-aprendizagem -, pois os conceitos de diversas disciplinas são relacionados à luz das questões concretas que se pretende compreender.

Aqui se poderia pensar não haver distinção com a interdisciplinaridade do currículo por competências, uma vez que o desenvolvimento de competências exigiria mesclar conhecimentos antes disciplinares com os saberes cotidianos em situações de aprendizagem apropriadas. Ocorre que, ao ser orientado pelas competências, a seleção e o ordenamento de conteúdos terão como fim os desempenhos profissionais e não a compreensão do exercício profissional como mediação de relações sociais de produção e dos processos produtivos como particularidade da realidade social.

Essa outra finalidade do currículo exige a ampliação do universo de seleção dos conteúdos. Como explicamos, por um lado, a dimensão técnico-organizacional do trabalho é somente um dos campos de referência da seleção de conteúdos, posto que os processos produtivos, como particularidade, seriam analisados e apreendidos em múltiplas dimensões que os relacionem à totalidade do real. Por outro lado, a aprendizagem promovida nesse sentido exige o aprofundamento científico dos conceitos, o que impõe a sua correlação com outros de um mesmo campo disciplinar. Portanto, a interdisciplinaridade não compromete a identidade epistemológica das disciplinas (Brasil, 2010), uma vez que a compreensão do todo exige captar as partes e as mediações em profundidade.

\section{O problema da relação teoria e prática}

Quanto à relação entre teoria e prática, o parecer é enfático em sua defesa e esta aparece nos princípios da valorização da experiência dos alunos, da contextualização na prática dos conhecimentos teóricos, da prática como organizadora do currículo, dentre outros. Já afirmamos o entendimento de que a competência profissional é sustentada por saberes que constituem síntese dos conhecimentos teóricos e da experiência. Uma questão a analisar, porém, é se tal síntese é geradora de condutas pragmáticas ou integradas à apreensão conceitual da realidade e produtoras, assim, de novos conhecimentos. Ou seja, a competência profissional pode se inscrever no universo pragmático da prática utilitária, ou no universo da práxis, dependendo de como se compreende a relação teoria-prática.

Os saberes produzidos no contexto da prática utilitária imediata colocam o homem em condições de orientar-se no mundo, de familiarizar-se com as coisas e manejá-las, mas não proporciona a compreensão das coisas e da realidade. A concepção pragmática aceita a suficiência desses saberes, pois considera a experiência subjetiva não só referência primeira que orienta o conhecimento e a ação humana, mas também o contexto de comprovação da validade do conhecimento, dada por sua 
utilidade prática. Nesses termos, a teoria devia ser entendida como as hipóteses de solução de problemas que, sendo eficientes experimental ou cognitivamente, comprovariam sua utilidade social e moral. Tal compreensão da teoria é coerente com a que o pragmatismo tem sobre a experiência ou prática como a continuidade entre os fenômenos naturais, os acontecimentos sociais e a experiência humana (Dewey, 1989).

A filosofia da práxis, ao contrário, compreende a prática como atividade objetiva e transformadora da realidade natural e social, a qual implica certo grau de conhecimento da realidade que busca transformar e das necessidades que movem tal transformação (Vázquez, 2007). A teoria é produto do trabalho de conhecer e apreender o real, que consiste em se elevar da experiência sensível ao pensamento, até a elucidação progressiva das contradições internas aos fenômenos que existem objetivamente.

Portanto, a prática transformadora no contexto da realidade - que não é somente utilitária e adaptadora - depende da atividade realizada no contexto da teoria, posto que o homem não pode conhecer o real a não ser pela análise dos fatos, reordenando-os, posteriormente, nas intrínsecas relações com a totalidade concreta. A função real da teoria científica é penetrar a superfície empírica da realidade e captar as relações que geram as formas aparentes ou estritamente sensíveis. Por isso, os conceitos teóricos da ciência não são redutíveis a conceitos observáveis. Eles procuram descrever os aspectos não observáveis da realidade, que se manifestam de forma contraditória (Kosik, 1976).

Na concepção de educação profissional contraposta a do Parecer Cordão não se trata apenas de relacionar a teoria com a prática. Trata-se de orientar a formação pela unidade dialética entre teoria e prática, o que implica apreender os fenômenos em suas mediações e contradições, elaborando-os no plano do pensamento como um conhecimento, uma teoria. A utilidade desta no retorno à prática está no fato de corresponder aos fundamentos do fenômeno estudado e não à sua aparência manifestável e sensível à experiência. Somente de posse desses fundamentos os sujeitos podem agir conscientemente de forma transformadora sobre o objeto de seu trabalho e de suas relações sociais. Por isso, à educação compete apresentar ao estudante os conceitos já elaborados sobre os fenômenos e levá-lo, pelo método, a novas construções conceituais que tanto estruturam suas práticas quanto permitem criticá-las e superá-las, não só no plano da subjetividade, mas também das relações sociais.

\section{Currículo modular: da flexibilidade à fragmentação}

A análise da organização curricular proposta pelo parecer identifica os módulos e os itinerários formativos como estratégias de flexibilização. De acordo com o parecer:

A organização curricular por módulos ou etapas com terminalidade profissional, segundo itinerários formativos organizados por eixos tecnológicos, é uma 
das formas de flexibilizar e organizar um currículo centrado na aprendizagem do aluno e no desenvolvimento contínuo de competências profissionais. Os módulos podem ser entendidos como um conjunto de competências profissionais que, estruturados pedagogicamente, respondem a uma etapa do processo formativo, e possuem terminalidade profissional se tiverem como referência básica uma ocupação reconhecida como útil no mercado de trabalho. (Brasil. CNE/CEB, 2011, p. 25)

Vê-se que as ocupações são a referência para a organização modular do currículo, agregando-se as respectivas competências em unidades pedagógicas autônomas (os módulos) que podem compor diferentes itinerários formativos, conforme demandas e necessidades da produção. O desenho de tais itinerários seria provocado por mudanças na produção que exigiriam do trabalhador o desenvolvimento de novas competências. O currículo flexível é, na verdade, o currículo fragmentado que propõe um tipo de rotatividade formativa. O trabalhador flexível, por sua vez, vem a ser aquele capaz de renovar permanentemente suas competências, aproveitando diversas oportunidades, dentre as quais, a oferta desses currículos flexíveis/fragmentados.

Essa lógica opõe-se à formação unitária configurada por proporcionar aos estudantes a apreensão dos fundamentos científicos e tecnológicos da produção e respectivas profissões. Profissionais assim formados certamente seriam flexíveis no sentido de terem a base que possibilita a rápida compreensão e o domínio de transformações e inovações produtivas. Ou seja, uma flexibilidade de natureza unitária que conduz os sujeitos ao enfrentamento dos desafios, proporcionada por uma formação chave para entender e enfrentar a realidade adversa da sociedade capitalista.

Ao contrário, o parecer propõe uma formação fragmentada, que exige do trabalhador uma permanente atualização, sem que este tenha os instrumentos para a ação autônoma e transformadora própria de uma práxis social e produtiva crítica. Trata-se, assim, de uma "CHAVE" que abre somente as desiguais oportunidades do mercado de trabalho aos quais trabalhadores competentes podem se adaptar.

\section{"A interdisciplinaridade como problema e como necessidade"18}

A questão da interdisciplinaridade é a forma de trabalho em alguns Institutos Federais que mais se aproxima do entendimento de muitos professores sobre o que seja a formação integrada prevista como alternativa de articulação entre o ensino médio e a educação profissional pelo decreto n. 5.154/04, incorporado à atual LDB pela lei n. 11.741/08. Nos termos da concepção de formação integrada que temos defendido - em termos breves, a educação profissional não apenas operacional, mas

18 A expressão consta, originalmente, de Frigotto (1993). A seção atual tem por base Ciavatta (2010). 
com seus fundamentos científicos e tecnológicos, históricos e sociais -, os processos de ensino e aprendizagem interdisciplinares tangenciam os objetivos da integração, mas não esgotam seu potencial formativo, principalmente, de compreensão da contraditória e desumana realidade social, da falta de perspectivas de futuro em que vive a grande maioria de nossos jovens alunos.

O Parecer Cordão recomenda que as escolas adotem a interdisciplinaridade como um aspecto da "filosofia de trabalho", mas o contexto da recomendação limita-se ao mercado de trabalho:

A Educação Profissional Tecnológica, com a oferta de cursos e programas superiores de Graduação e de Pós-graduação, está comprometida com os objetivos de incentivar o desenvolvimento da capacidade empreendedora e da compreensão do processo tecnológico, em suas causas e efeitos; incentivar a produção e a inovação científico-tecnológica e suas respectivas aplicações no mundo do trabalho; desenvolver competências profissionais e tecnológicas, gerais e especificas, para a gestão de processos e a produção de bens e serviços; propiciar a compreensão e a avaliação dos impactos sociais, econômicos e ambientais resultantes da produção, gestão e incorporação de novas tecnologias; promover a capacidade de continuar aprendendo e de acompanhar as mudanças que ocorrerem nas suas condições de trabalho e de exercício profissional. Para tanto, incumbe das Instituições Educacionais que oferecem tais programas adotar como flosofia de trabalho a flexibilidade, a interdisciplinaridade, a contextualização e a atualização permanente de seus cursos, currículos e programas, bem como garantir a identidade, a utilidade e a clareza na identificação dos perfis profissionais de conclusão dos seus cursos, programas e correspondentes organizações curriculares. (Brasil. CNE/CEB, 2011, p. 20, grifos nossos)

Não é este sentido restrito que damos ao termo. Entendemos que a aproximação com a realidade e seu reconhecimento como um saber tem gerado diferentes lógicas de construção do conhecimento. A interdisciplinaridade é uma das formas de aproximação com a realidade. Historicamente, os pensadores dedicaram-se a tentar explicar o que é a realidade, como o ser humano acolhe e incorpora em si a realidade, como o sujeito que conhece alcança o objeto que se dá a conhecer. Assim, tantas são as visões de mundo e de realidade, quantos são os caminhos delineados ou estabelecidos para se chegar à "verdade”, para desnudar o objeto na sua interioridade, na sua natureza, no seu desenvolvimento e nas suas relações.

Em geral, na produção do conhecimento reconhecido como científico, nas ciências humanas e sociais, entre as quais a educação, aceita-se que a explicitação do método e o rigor na sua aplicação conferem ao conhecimento obtido a qualidade de científico ou de verdadeiro. O próprio alargamento das fronteiras da ciência e das novas formas de o ser humano se relacionar com o mundo, inclusive as formas destrutivas que têm ameaçado a sobrevivência do gênero humano, as 
políticas ditatoriais, os enriquecimentos ilícitos à custa do empobrecimento de milhões, tem trazido à luz a complexidade do conhecimento dito verdadeiro e os múltiplos saberes de que é portadora a humanidade na sua história milenar e, em grande parte, desconhecida. ${ }^{19} \mathrm{Um}$ conceito correlato a essa discussão, hoje, é o de desenvolvimento que de um lado é apresentado como a oportunidade de geração de trabalho e renda, e de outro deixa evidente a existência do desenvolvimento econômico em detrimento do desenvolvimento social, do bem-estar da vida nos seus aspectos fundamentais (moradia, saúde, educação etc.).

É nesta complexidade de relações que se insere a interdisciplinaridade como problema e como necessidade na produção do conhecimento. Isto porque, se os fenômenos não se dão a conhecer de imediato, seu conhecimento será sempre resultado de nossa capacidade, desvelando o maior número possível de aspectos de sua totalidade social. O que exige certo détour, um percurso além das aparências (Kosik, 1976), uma busca de suas mediações, dos processos sociais que os constituem em situação de tempo e espaço, transformação e historicidade (Franco, 2001).

São esses conhecimentos que levam à identificação de contradições sociais inerentes ao mundo do trabalho e da educação e ao seu obscurecimento, senão negação, nos currículos escolares. Essa questão está presente, principalmente, no que diz respeito à educação profissional e tecnológica para o desempenho nos setores produtivos e de serviços. Os empresários tratam a regulamentação das relações de trabalho como custo, e não como investimento na mão de obra qualificada, que reverte em maior produtividade. Para os trabalhadores, entretanto, ela significa garantias conquistadas pela legislação trabalhista, ao longo do século $\mathrm{XX}$, e que estão sendo perdidas a partir de 1990.

Vimos recentemente, em escolas técnicas, a confusão entre mercado de trabalho e mundo do trabalho. $\mathrm{O}$ primeiro termo diz respeito à geração e demanda de postos ou de oportunidades de trabalho, é a "esfera que circunscreve as práticas sociais pelas quais a força de trabalho, sob determinadas normas e leis, é comprada e vendida", sob uma correlação de forças desiguais entre os empregadores, os donos do capital, e os trabalhadores. O termo obscurece as condições de trabalho, as relações hierárquicas, a submissão do trabalho assalariado que presidem essas relações (Fidalgo; Machado, 2000, p. 204-5).

O segundo termo, mundo ou mundos do trabalho, ideia aparentemente vaga, tem seu uso definido em referência ao trabalho em geral e às condições de trabalho e de vida dos trabalhadores, à sua cultura, ao seu pertencimento à classe trabalhadora, à história da classe operária (Hobsbawm, 1987). Em que escolas se fala do trabalho, do que ele significa nas sociedades capitalistas? Preparamos para o trabalho sem

19 Estes e outros aspectos desta reflexão constam, particularmente, do tratamento dos conceitos de totalidade e das mediações, de Ciavatta (2001). 
discutir o seu significado mais profundo, a exploração dos trabalhadores e a reprodução das desigualdades sociais. Fora desse contexto, a interdisciplinaridade torna-se apenas uma técnica útil ao ensino, mas não, necessariamente, à formação humana.

\section{CONSIDERAÇÕES FINAIS}

O termo "diretrizes" não é novo na educação brasileira, mas a política de sua utilização como instrumento de obtenção do consenso dos professores e das escolas, por meio da distribuição extensa de publicações, com o apoio de instrumentos normativos, decretos e pareceres do Conselho Nacional de Educação - é um fato novo que marcou a ação do governo Fernando Henrique Cardoso por quase uma década (1994-2002). Sua difusão, como ideário para o nível médio e, particularmente, para a educação profissional, foi tão orgânica que se manteve ao longo do governo Luiz Inácio Lula da Silva (2003-2010), perdurando no atual governo Dilma Rousseff.

Apoiado em documentos dos organismos internacionais e com a atuação no governo, profissionais com experiência nessas agências (a exemplo do ex-Ministro da Educação, Paulo Renato de Souza) desenvolveram um intenso trabalho de convencimento e de concessão de recursos (a exemplo do PROEP, Programa de Expansão da Educação Profissional), disseminando uma prática, de certa forma, clientelista, de imposição dos projetos do governo. Uma de suas ideias, o ensino e a avaliação de competências, teve ampla aceitação como ideologia, apesar do difícil entendimento de como aplicá-la substituindo os tradicionais conceitos de qualificação, conhecimentos e habilidades na formação profissional.

Sua funcionalidade aos segmentos empresariais impõe uma visão adaptativa e acrítica ao mercado de trabalho em um momento de mudanças nas bases produtivas, de redução do nível de emprego e de transferência de responsabilidade aos trabalhadores de se manterem empregados através da formação - sob a ideia de empregabilidade, laboralidade, empreendedorismo, amplamente criticadas, mas de grande influência na população. Contraria uma concepção formativa, apoiada no conceito de politecnia, defendida no projeto original da LDB nos anos 1980, mas derrotada na versão final da lei n. 9.394/96.

É sobre esta base que se apoiam as atuais DCN elaboradas pela Câmara de Educação Básica do Conselho Nacional de Educação, às quais se contrapõe o documento alternativo elaborado pelo Grupo de Trabalho (ver seção Documentos deste número da $R B E$ ), que teve suas atividades apoiadas pelo MEC na forma de infraestrutura para reuniões em Brasília em 2010 - sem gratificações de qualquer espécie, apenas com o suporte de passagens e hospedagem. Neste texto, procuramos analisar alguns aspectos reiterados na proposta do Relator da CEB/CNE, Professor Cordão, a saber: o sentido da ideia de diretrizes na legislação básica da educação no Brasil; a "CHAVE" como núcleo da proposta de diretrizes; concepções de currículo em disputa na educação profissional; o problema da relação teoria e prática; flexibilidade e fragmentação no currículo modular; interdisciplinaridade. 
As DCN, inauguradas no governo Fernando Henrique Cardoso, tornam-se instrumento de direção política e cultural da sociedade por intermédio da educação. Elas adquirem, assim, um caráter estratégico, pois confirmam a escola como aparelho privado de hegemonia. O caráter estratégico dessa disputa é, em certa medida, determinado por contradições surgidas com a reestruturação produtiva e a mudança da base técnico-científica da produção em direção à especialização flexível. ${ }^{20}$ Essas transformações têm uma dimensão tanto cínica quanto perversa que, contraditoriamente, aponta para a necessidade de ampliação da escolaridade e de requalificação dos trabalhadores.

Vários estudos, ${ }^{21}$ porém, já demonstraram que o requerimento da escolaridade não é tanto em razão da necessidade de que o trabalhador tenha conhecimentos científicos - dada a simplificação dos procedimentos de trabalho possibilitada pela tecnologia microeletrônica e digital molecular -, mas sim de se prepará-lo e adequá-lo para enfrentar a flexibilidade do trabalho internamente à produção ou fora dela; neste caso, estando desempregado e tendo de sobreviver. Mas o que é significativo nesse novo contexto para a relação entre trabalho e educação é que, diferente de muitos outros países, no Brasil, a política e a gestão da educação dos trabalhadores foram historicamente entregues aos homens de negócios, ao capital. Nesse momento, é ao se tornar objeto de disputa entre as classes que a educação básica e profissional dos trabalhadores se torna relevante, por motivos diferentes, ${ }^{22}$ tanto para o capital quanto para os trabalhadores. Abre-se, assim, um flanco de contradições que contribuem para potencializar a elaboração e o desenvolvimento de projetos educacionais na perspectiva dos trabalhadores e não do capital. Para isso, entretanto, é preciso agir na construção de uma nova hegemonia.

No Brasil, a história da política da educação dos trabalhadores e sua regulamentação curricular expressam as marcas do Estado que afiançou a consolidação de um capitalismo dependente, comprometido com os interesses burgueses. As regulamentações na educação sempre cumpriram a finalidade de obtenção do consentimento dos governados, seja diretamente pela coerção, seja desta revestida de hegemonia. Neste último caso, a relação entre sociedade civil e Estado amplia-se, especialmente pela participação organizada da primeira para disputar o sentido das políticas públicas.

$\mathrm{Na}$ construção de hegemonia pelos trabalhadores o conhecimento torna-se mediação de uma relação pedagógica entre grupos que querem educar a si próprios

20 Sobre esse conceito, ver Antunes (2005).

21 Ver, por exemplo, Kuenzer (2000) e Antunes (2005), dentre outros.

22 No caso do capital, a educação dos trabalhadores é vista como fato de produtividade e de seletividade, associada a elementos de filantropia e de controle da ordem social. No caso dos trabalhadores, o direito à educação sempre foi defendida como inegociável, apesar de historicamente negado, como condição necessária para sua emancipação.

$\begin{array}{llll}\text { Revista Brasileira de Educação } & \text { v. } 17 & \text { n. } 49 \text { jan.-abr. } 2012\end{array}$ 
para a arte do governo. Ao identificar-se com a efetiva democracia, ela promove transformações profundas na estrutura e na superestrutura, gerando a crescente socialização do poder.

Com essa compreensão, concluímos que o papel de educadores organizados e mobilizados para a ação teórico-prática da transformação social inclui a construção conceptual capaz de unificar culturalmente os trabalhadores para a construção de uma nova hegemonia. Gramsci (1991, p. 9) nos afirma: "a escola é o instrumento para elaborar os intelectuais de diversos níveis”. Como condição para a construção da hegemonia pelos trabalhadores, então, a escola deve ser disputada na direção de uma "escola única inicial de cultura geral, humanista, formativa, que equilibre com equanimidade o desenvolvimento da capacidade de trabalhar manualmente (tecnicamente, industrialmente) e o desenvolvimento das capacidades de trabalho intelectual" (idem, p. 118). É nesses termos que a disputa das diretrizes curriculares nacionais da educação profissional e do ensino médio tem sido travada atualmente.

\section{REFERÊNCIAS}

ANTUNEs, Ricardo. O caracol e sua concha: ensaios sobre a nova morfologia do trabalho. São Paulo: Boitempo, 2005.

Bomfim, Alexandre. Desvendando a área de Trabalho e Educação: estudo sobre a produção e os produtores do GT Trabalho e Educação da ANPEd. 2006. Tese (Doutorado em Educação) - Pontifícia Universidade Católica, Rio de Janeiro.

BRASIL. Lei n. 9.394, de 20 de dezembro de 1996. Diretrizes e Bases da Educação Nacional. Educação profissional: legislação básica. Brasília, DF: PROEP, 1998.

. Decreto n. 5.154 de 23 de julho de 2004. Regulamenta o $§ 2^{\circ}$ do art. 36 e os art. 39 a 41 da Lei n. 9.394, de 20 de dezembro de 1996. Disponível em: <http://www. portal.mec.gov.Br/setec/arquivos/pedf_legislação/técnico/legisla_técnico_parecer 1699. pdf>. Acesso em: 26 fev. 2009.

. Decreto n. 2.208, de 17 de abril de 1997. Educação profissional: legislação básica. Brasília, DF: PROEP, 1998.

. Lei n. 11.741, de 16 de julho de 2008. Altera dispositivos da Lei n. 9.394, de 20 de dezembro de 1996. Disponível em: <http://www.legislação.planalto.gov.br>. Acesso em: 26 fev. 2009.

. Diretrizes Curriculares Nacionais para a Educação Profissional Técnica de Nível Médio em Debate. Texto para discussão. Brasília, 2010.

BRASIL. CNE/CEB. Atualização das Diretrizes Curriculares Nacionais para a Educaşão Profissional Técnica de Nivel Médio. Brasília: CNE.CEB, 2011.

. Parecer n. 16, de 5 de outubro de 1999. Diretrizes Curriculares Nacionais para a educação profissional Nível Técnico. 1999. Disponível em: <http://www.portal.mec.gov. 
$\mathrm{Br} /$ setec/arquivos/pedf_legislação/técnico/legisla_técnico_parecer1699.pdf>. Acesso em: 26 fev. 2009.

. Parecer n. 15/98, de 1 de junho de 1998. Diretrizes Curriculares Nacionais para o Ensino Médio. Brasília, DF, 1998.

BRAsil. MEC.SETEC. Parâmetros Curriculares Nacionais: Ensino Médio. Brasília: MEC.SETEC, 2000a.

- Referenciais Curriculares Nacionais para a Educą̧ão Profissional de Nivel Técnico. Brasília: MEC. SETEC, 2000b.

. Educação Profissional Técnica de Nivel Médio Integrada ao Ensino Médio. Documento Base. Brasília: MEC. SETEC. Disponível em: <http//www.portal.mec.gov. $\mathrm{br} /$ setec/arquivos/pdf/documento_base.pdf >. Acesso em: 13 set. 2011.

BRAsIL. INEP. A profissionalização do ensino na Lei n. 5.692/71. Brasília: INEP, 1982.

Bruni, José Carlos; Nogueira, Marco Aurélio. Esclarecimento. In: MarX, Karl.; Engels, Friedrich. A ideologia alemã. São Paulo: Ciências Humanas, 1979.

CDEs. As desigualdades na escolarização no Brasil: Relatório de observação n. 4. Brasília: Presidência da República, Conselho de Desenvolvimento Econômico e Social - CDES, 2011.

DeLORS, Jaques. Educação: um tesouro a descobrir. Relatório para a UNESCO da Comissão Internacional sobre Educação para o século XXI. São Paulo: UNESCO; MEC; Cortez, 1998.

Dewey, John. Cómo pensámos. Buenos Aires: Paidós, 1989.

Fidalgo, Fernando; Machado, Lucília (Ed.). Dicionário da educação profissional. Belo Horizonte: NETE; UFMG, 2000.

Franco, Maria Ciavatta. Formação profissional para o trabalho incerto: um estudo comparativo Brasil, México e Itália. In: FrigotTo, Gaudêncio. Educação e crise do trabalho: perspectivas de final de século. Petrópolis: Vozes, 1998.

. O conhecimento histórico e a questão teórico-metodológica das mediações. In: FrigotTo, Gaudêncio; Franco, Maria Ciavatta. (Org.). Teoria e educação no labirinto do capital. Petrópolis: Vozes, 2001.

. A formação integrada e a questão da interdisciplinaridade. In: ENCONTRO de Professores do Instituto Federal do Rio Grande do Norte, 1., 2010, Natal. Franco, Maria Ciavatta; Trein, Eunice. O percurso teórico e empírico do GT Trabalho e Educação: uma análise para debate. Revista Brasileira de Educação, Rio de Janeiro: ANPEd; Campinas: Autores Associados, n. 24, p. 140-164, 2003.

Franco, Maria Ciavatta; Simon, Maria Célia M. M. Trabalho e educação: a reforma necessária no contexto da Revolução de Trinta. Revista Brasileira de Estudos Pedagógicos, Brasília: INEP, v. 68, n. 160, p. 560-583, set./dez. 1987. 
Franco, Maria Ciavatta; FrigotTo, Gaudêncio; Ramos, Marise. Ensino médio integrado: concepção e contradições. São Paulo: Cortez, 2005.

FRIGOTTO, Gaudêncio. A interdisciplinaridade como problema e como necessidade nas ciências sociais. Educação e Realidade, Porto Alegre: UFRGS, v. 18, n. 2, p. 63-72, 1993.

Gómez, Angel. Competências ou pensamento prático? A construção dos significados de representação e ação. In: SACRISTÁN, José Gimeno. Educar por competências. O que há de novo? Porto Alegre: Artmed, 2011.

Gramsci, Antonio. Os intelectuais e a organização da cultura. Rio de Janeiro: Civilização Brasileira, 1991.

Harvey, David. Condição pós-moderna. São Paulo: Loyola, 1992.

Hobsbawm, Eric J. Mundos do trabalho. Rio de Janeiro: Paz e Terra, 1987.

IAnNi, Octávio. Estado e planejamento econômico no Brasil. Rio de Janeiro: Civilização Brasileira, 1991.

Kosık, Karel. Dialética do concreto. Rio de Janeiro: Paz e Terra, 1976.

Kuenzer, Acácia. Competência como práxis: os dilemas da relação entre teoria e prática na educação dos trabalhadores. Boletim Técnico do Senac, Rio de Janeiro, v. 29, n. 1, jan./ abr. 2003. Disponível em: <http://www.senac.br/BTS/291/boltec291b.htm>. Acesso em: 12 fev. 2012.

Lopes, Alice. Possibilidades do currículo integrado. Rio de Janeiro: Eduerj, 1998.

. Políticas de integração curricular. Rio de Janeiro: Eduerj, Faperj, 2008.

Moreira, Antonio; Silva, Tomaz Tadeu. Currículo, cultura e sociedade. São Paulo: Cortez Editora, 2001.

Mendes, Durmeval T. (Coord.). Filosofia da educação brasileira. Rio de Janeiro: Civilização Brasileira, 1983.

Netto, José Paulo. Desigualdade, pobreza e serviço social. Em Pauta, Revista da Faculdade de Serviço Social da Universidade do Estado do Rio de Janeiro, Ed. Revan, n. 19, p. 135-170, 2007.

Ramos, Marise. Do ensino técnico à educação tecnológica: (a)-historicidade das políticas públicas dos anos 90. 1995. Dissertação (Mestrado em Educação) - Universidade Federal Fluminense, Rio de Janeiro.

Romanelli, Otaíza. História da educação no Brasil: 1930-1973. Petrópolis: Vozes, 1978.

Rothen, José C. O Conselho Federal de Educação nos Bastidores da Reforma Universitária de 1968. In: Congresso Brasileiro de História da EduCAÇÃo, III., 2004, Curitiba. Curitiba: Pontifícia Universidade Católica do Paraná, 2004. p. 1-11. Disponível em: <http://www.sbhe.org.br/novo/congressos/cbhe3/Documentos/Individ/ Eixo3/236.pdf>. Acesso em: 14 set. 2011. 
Sacristán, José Gimeno. Dez teses sobre a aparente utilidade das competências em educação. In: . (Org.). Educar por competências. O que há de novo? Porto Alegre: Artmed, 2011.

SaVIani, Dermeval. Pedagogia histórico-crítica. Campinas: Autores Associados, 2005. . História das ideias pedagógicas no Brasil. Campinas: Autores Associados, 2007. Shiroma, Eneida Oto; Moraes, Maria Célia M.; Evangelista, Olinda. Política educacional. Rio de Janeiro: DP\&A, 2003.

Trein, Eunice; PicAnço, Iracy S. O GT Trabalho e Educação. In: ANPEd. Histórico dos grupos de trabalho. Belo Horizonte: ANPEd, 1995.

TreIn, Eunice. Entrevista. Revista do NETE, Belo Horizonte: UFMG, n. 0, p. 32-40, jul./dez. 1996.

VÁsQuez, Adolfo Sanchéz. Filosofia da práxis. São Paulo: Expressão Popular, 2007.

\section{SOBRE AS AUTORAS}

Maria Ciavatta é doutora em educação pela Pontifícia Universidade Católica do Rio de Janeiro (PUC-Rio). Professora titular da Universidade Federal Fluminense (UFF) e professora visitante da Universidade do Estado do Rio de Janeiro (UERJ).

E-mail: mciavatta@terra.com.br

MARise Ramos é doutora em educação pela Universidade Federal Fluminense (UFF). Professora adjunta da Universidade do Estado do Rio de Janeiro (UERJ) e professora da Escola Politécnica de Saúde Joaquim Venâncio (EPSJV) da Fundação Oswaldo Cruz (FIOCRUZ).

E-mail:mramos@fiocruz.br

Recebido em agosto de 2011 Aprovado em outubro de 2011 


\section{MARIA CIAVATTA E MARISE RAMOS}

\section{A "era das diretrizes": a disputa pelo projeto de educação dos mais pobres}

Este texto analisa, criticamente, a proposta de atualização das diretrizes curriculares nacionais da educação profissional técnica de nível médio relatada no Conselho Nacional de Educação pelo professor Francisco Cordão, enfocando os seguintes aspectos: a CHAVE como núcleo da proposta de diretrizes; concepções de currículo em disputa na educação profissional; o problema da relação teoria e prática; flexibilidade e fragmentação no currículo modular; interdisciplinaridade. Para isso, retoma inicialmente o sentido das diretrizes na legislação básica da educação no Brasil e a incorporação do tema currículo pela área Trabalho e Educação, à medida que essas se tornam instrumento de direção política e cultural da sociedade no contexto de crise do capital. Discute, ainda, em contraponto à proposta, princípios expostos no documento alternativo elaborado pela sociedade civil e conclui sobre a importância da disputa pela concepção de educação dos trabalhadores no Brasil como meio de construção da contra-hegemonia.

Palavras-chave: Diretrizes Curriculares Nacionais; educação profissional; currículo por competências; formação integrada.

The "era of guidelines": the struggle for the education project of the poorest

This document examines critically the proposed update of the national curriculum guidelines of secondary school professional technical education reported in the National Council of Education (CNE) by Professor Francisco Cordão. Its focus on the following aspects: the KEY as the core of the proposed guidelines; conceptions of curriculum in professional education; the problem of the theory and practice, flexibility and fragmentation in the modular curriculum, interdisciplinarity. For this, initially takes the meaning of the guidelines in the legislation's basic education in Brazil and the incorporation of the subject curriculum in the area of Work and Education, as these become an instrument of political and cultural direction of society in the context of the crisis of capital. Also addresses, in contrast to the proposed principles outlined in the alternative document elaborated by civil society and concludes about the importance of the dispute for the design of professional education in Brazil as a means of building counter-hegemony.

Keywords: National Curriculum Guidelines; professional education; curriculum competency; integrated training. 


\section{La "era de las directrices": la lucha por el proyecto de educación de los más pobres}

Este articulo examina críticamente la propuesta de actualización de los lineamientos curriculares nacionales de formación profesional secundaria técnica reportado en el Consejo Nacional de Educación por el profesor Francisco Cordón, centrándose en los siguientes aspectos: la CLAVE como el núcleo de las directrices propuestas, concepciones del plan de estudios en disputa en la formación profesional, el problema de la teoría y la práctica, la flexibilidad y la fragmentación en el plan de estudios modular, la interdisciplinariedad. Para ello, inicialmente toma el significado de las directrices de la educación básica de la legislación en Brasil y la incorporación del plan de estudios en la área de Trabajo y Educación, ya que se convierta en un instrumento de la sociedad política y cultural en el contexto de la crisis del capital. También se ocupa, en oposición a la propuesta, de los principios alternativos descritos en el documento elaborado por la sociedad civil y concluye sobre la importancia del concurso para la educación de los trabajadores en Brasil como un medio de construcción de contrahegemonía.

Palabras clave: directrices del currículo nacional; la educación profesional; la competencia curricular; la formación integrada. 